\title{
Frequent expression of smooth muscle markers in malignant fibrous histiocytoma of bone
}

\author{
T Ueda, N Araki, M Mano, A Myoui, S Joyama, S Ishiguro, H Yamamura, K Takahashi, \\ I Kudawara, H Yoshikawa
}

See end of article for authors' affiliations

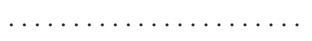

Correspondence to: Dr T Ueda, Department of Orthopaedic Surgery, Osaka University Graduate School of Medicine, 2-2 Yamada-oka, Suita, Osaka 565-0871, Japan; vedat@ort.med.osaka-u.ac.jp

Accepted for publication 27 June 2002

\begin{abstract}
Background/Aims: Malignant fibrous histiocytoma (MFH) of bone, a relatively rare primary malignant bone tumour, is a distinct clinicopathological entity as opposed to MFH derived from soft tissue. Although the true histogenesis of this condition is still controversial, a considerable number of cases of MFH in soft tissue show positive immunohistochemical reactivity for muscle markers such as desmin, common muscle actin (HHF35), and $\alpha$ smooth muscle actin (SMA), suggesting that MFH cells are myofibroblastic in nature.

Methods: This study investigated immunoreactivity for several different muscle markers in 19 cases of MFH of bone together with reverse transcription polymerase chain reaction (RT-PCR) analysis on frozen tissue samples that were available in four cases, and compared the data with those found in 11 cases of osteosarcoma and 11 cases of soft tissue MFH treated over the same period.

Results: Immunohistochemistry revealed that MFH of bone showed relatively frequent expression of smooth muscle markers, including calponin (nine cases), $\alpha$-SMA (nine cases), and SM22 $\alpha$ (18 cases), and this was confirmed by RT-PCR analysis. However, only one, two, and three cases of MFH of bone showed positive staining for desmin, MyoD1, and HHF35, respectively. Similarly, 11 osteosarcoma cases were relatively frequently positive for $\alpha$-SMA (five cases), calponin (four cases), and SM22 $\alpha$ (seven cases), and less frequently positive for desmin (one case), MyoD1 (none), and HHF35 (none). In contrast, very few MFH of soft tissue cases $(n=11)$ showed positive reactivity for all of these muscle markers. It has recently been reported that human bone marrow stromal cells also express various kinds of smooth muscle markers including $\alpha$-SMA and calponin.

Conclusions: These results suggested that MFH of bone may derive from mesenchymal stromal cells in bone marrow and has a more myofibroblastic differentiation than soft tissue MFH.
\end{abstract}

M alignant fibrous histiocytoma (MFH) of bone is a relatively rare, malignant bone tumour that comprises less than $2 \%$ of all primary malignant bone tumours. ${ }^{1}$ This distinct entity was first described by Feldman and Norman ${ }^{2}$ in 1972, and by Mirra and colleagues ${ }^{3}$ in 1974 as a counterpart of MFH derived from soft tissue. Most cases of MFH of bone were previously classified as pleomorphic or poorly differentiated fibrosarcomas, pleomorphic reticulum cell sarcomas, spindle cell and giant cell sarcomas, or osteolytic/fibroblastic osteosarcomas. ${ }^{45}$ Although the true histogenesis of this disease is still controversial, MFH of bone is now a widely accepted clinicopathological entity. ${ }^{15-11}$ It is microscopically characterised by an admixture of fibroblastic or myofibroblastic spindle cells with a storiform or cartwheel pattern and histiocyte-like pleomorphic cells accompanied by a varying number of giant cells and inflammatory cell infiltrations. It can also include varying amounts of stromal collagen and myxoid matrix. Because the histological appearance of $\mathrm{MFH}$ of bone can vary greatly, it is often difficult to differentiate it from other malignant bone tumours, such as osteosarcoma, fibrosarcoma, leiomyosarcoma, dedifferentiated chondrosarcoma, and even malignant lymphoma.

\footnotetext{
"Although the true histogenesis of this disease is still controversial, malignant fibrous histiocytoma of bone is now a widely accepted clinicopathological entity"
}

No specific immunohistochemical markers have been recognised for MFH of soft tissue, and a considerable number of cases of MFH show positive immunoreactivity for muscle markers such as desmin, common muscle actin (HHF35), and $\alpha$ smooth muscle actin ( $\alpha$-SMA), ${ }^{12}$ suggesting a "myoid" or myofibroblastic differentiation of MFH cells. However, the immunohistochemical study of MFH of bone is very limited because of its relative rarity compared with MFH of soft tissue. ${ }^{813}{ }^{14}$ In our present study, we have looked at immunoreactivity for various muscle markers and undertaken reverse transcription polymerase chain reaction (RT-PCR) analysis in 19 cases of MFH of bone. We further discuss the importance of their expression in MFH of bone.

\section{MATERIALS AND METHODS \\ Patients}

Between 1979 and 1997, 29 patients with MFH of bone were treated at Osaka University Medical Hospital, Osaka Medical Center for Cancer and Cardiovascular Diseases, and Osaka National Hospital. Of these 29 patients, we selected the 19 consecutive patients whose paraffin wax embedded, noncalcified biopsy and/or surgically resected tumour specimens were available for immunohistochemical staining. There were 12 male and seven female patients, with ages ranging from 15 to 77 years (mean, 39.9). The locations of the primary tumours were: 11 cases in the femur, two cases in the ilium, two cases in the fibula, and one case each in the scapula, humerus, tibia, and lumbar spine. All cases were histologically reviewed and confirmed as MFH of bone by two of the authors (TU and

Abbreviations: $A B C$, avidin-biotin complex; GAPDH, glyceraldehyde-3-phosphate dehydrogenase; HHF35, common muscle actin; MFH, malignant fibrous histiocytoma; RT-PCR, reverse transcription polymerase chain reaction; $\alpha$-SMA, $\alpha$ smooth muscle actin 
Table 1 Antibodies used in our immunohistochemical study

\begin{tabular}{lllll}
\hline $\begin{array}{l}\text { Antibody/ } \\
\text { antigen } \\
\text { pretreatment }\end{array}$ & Clone & Dilution & Source & Mirowave \\
\hline Calponin & hCP & $1 / 4000$ & Sigma, St Lovis, Missouri, USA & + \\
$\alpha$-SMA & 1A4 & $1 / 500$ & Sigma & - \\
Desmin & D33 & $1 / 200$ & Dako, Carpinteria, California, USA & + \\
CMA & HHF35 & $1 / 50$ & Dako & - \\
MyoD1 & 5.8A & $1 / 200$ & Dako & + \\
SM22 $\alpha$ & Polyclonal (rabbit) & $1 / 500$ & H Yamamura et al & + \\
\hline
\end{tabular}

CMA, common muscle actin; SMA, smooth muscle actin.

MM). Fourteen cases were classified as predominantly fibroblastic/fibrohistiocytic (storiform-pleomorphic) type, four as predominantly histiocytic or xanthomatous type, and one as giant cell type. Two cases categorised as the first two types each showed pronounced inflammatory cell infiltrations. No myxoid variants were seen in the present series. All 19 cases were histologically high grade. We also examined 11 cases of conventional osteosarcoma and 11 cases of MFH of soft tissue treated over the same period, as control groups. The location of the primary tumours in osteosarcoma cases included femur (seven cases; distal, six; proximal, one), proximal tibia (two cases), humerus (one case), and ilium (one case). All cases were high grade and the histological subtype was osteoblastic in nine cases, chondroblastic in one case, and telangiectatic in one case. With regard to the cases of soft tissue MFH, in two cases each the primary location was the thigh, leg, shoulder, and buttock, and in one case each it was the back, groin, and retroperitoneum. There were five cases of grade 2 and six of grade 3 and the histological subtype was storiform-pleomorphic variant in eight cases and myxoid variant in three.

\section{Immunohistochemistry}

Routinely processed, formalin fixed, paraffin wax embedded tissue specimens were obtained from biopsies and/or surgical resections of the primary tumours in all 19 cases. Based on the examination of haematoxylin and eosin stained slides, one representative paraffin wax block sample from each case was chosen for immunohistochemical staining using the avidinbiotin complex (ABC) method. Table 1 lists the antibodies for muscle markers used in our study. Monoclonal antibodies against calponin (clone hCP) and $\alpha$-SMA (clone lA4) were purchased from Sigma (St Louis, Missouri, USA). The specificity of the clone hCP monoclonal antibody to the basic (hl) calponin isoform has been verified by immunoblot analysis with alkaline phosphatase staining (Bio-Rad, Hercules, California, USA), as described previously. ${ }^{15}$ Monoclonal antibodies against desmin (clone D33), common muscle actin (clone HHF35), and MyoDl (clone 5.8A) were purchased from Dako (Carpinteria, California, USA). A polyclonal antibody specific for the SM $22 \alpha$ protein was generated in rabbits, as described previously. ${ }^{16}$ The $4 \mu \mathrm{m}$ thick sections mounted on poly-L-lysine coated microslides were dewaxed in xylene, dehydrated through graded alcohol, and immersed in 70\% methanol with $\mathrm{H}_{2} \mathrm{O}_{2}$ to inhibit any endogenous peroxidase activity. Then, if necessary, antigen retrieval was performed for several antibodies (those directed against calponin, desmin, MyoD1, SM22 $\alpha$ ) using a commercial $400 \mathrm{~W}$ microwave oven (Toshiba ERT 330; Tokyo, Japan) four times for five minutes each in a $10 \mathrm{mM}$ citrate buffer $(\mathrm{pH} 7.0) .{ }^{17}$ The sections were reacted with the primary antibody overnight at $4^{\circ} \mathrm{C}$. They were then incubated with biotinylated antimouse or antirabbit immunoglobulin for 30 minutes, and subsequently stained using the $\mathrm{ABC}$ method. Diaminobenzidine was used as a chromogen, and the slides were counterstained with haematoxylin. Appropriate positive and negative controls were included in each staining procedure.

Tumour cells were considered positive if definite cytoplasmic staining distant from the edge of the section or areas of necrosis was observed. The extent of immunostaining in each specimen was scored by two independent observers (TU and MM) according to the number of stained tumour cells, as follows:,$++>50 \%$ positive;,$+ 10-50 \%$ positive;,$-<10 \%$ positive or no staining.

\section{RT-PCR analysis}

We also performed RT-PCR analysis for the expression of the basic (h1) and neutral (h2) calponin, $\alpha$-SMA, and SM22 $\alpha$ genes on frozen tumour samples that were available from four cases of MFH of bone. Tumour tissues were frozen immediately after surgical removal and stored at $-80^{\circ} \mathrm{C}$ until extraction of RNA. Total RNA was extracted from the tumour tissues using the Isogen RNA extraction kit (Nippon Gene, Toyama, Japan). RT of $2 \mu \mathrm{g}$ of total RNA was carried out using the reaction mixture "ready to go you prime first strand beads" (Pharmacia, Uppsala, Sweden) in the presence of $0.2 \mu \mathrm{g}$ of random hexamer primer. After 60 minutes of incubation at $37^{\circ} \mathrm{C}, 0.5 \mu \mathrm{M}$ of each of the forward and reverse primers, $200 \mu \mathrm{M}$ of each dNTP mixture, and $2.5 \mathrm{U}$ of Taq DNA polymerase (Pharmacia) were added to $8 \mu \mathrm{l}$ of the first strand

Table 2 Immunoreactivity for muscle markers in MFH of bone, in comparison with those in osteosarcoma and MFH of soft tissue

\begin{tabular}{|c|c|c|c|c|c|c|c|c|c|}
\hline & \multicolumn{3}{|c|}{ MFH of bone $(n=19)$} & \multicolumn{3}{|c|}{ Osteosarcoma $(n=11)$} & \multicolumn{3}{|c|}{ MFH of soft tissue $(n=11)$} \\
\hline & ++ & + & - & ++ & + & - & ++ & + & - \\
\hline$\alpha-S M A$ & 2 & 7 & $10(47 \%)$ & 0 & 5 & $6(45 \%)$ & 2 & 1 & $8(27 \%)$ \\
\hline Calponin & 1 & 8 & $10(47 \%)$ & 1 & 3 & $7(36 \%)$ & 0 & 1 & $10(9 \%)$ \\
\hline $\operatorname{SM} 22 \alpha$ & 7 & 11 & $1(95 \%)$ & 1 & 6 & $4(64 \%)$ & 1 & 1 & $9(18 \%)$ \\
\hline Desmin & 0 & 1 & $18(5 \%)$ & 0 & 1 & $10(9 \%)$ & 0 & 2 & $9(18 \%)$ \\
\hline MyoD1 & 0 & 2 & $17(11 \%)$ & 0 & 0 & $11(0 \%)$ & 0 & 0 & $11(0 \%)$ \\
\hline HHF35 & 0 & 3 & $16(16 \%)$ & 0 & 0 & $11(0 \%)$ & 0 & 3 & $8(27 \%)$ \\
\hline
\end{tabular}

,$++>50 \%$ positive $;+10-50 \%$ positive (including focal/scattered + ),$-<10 \%$ positive or no staining. The figures in parenthesis are the percentages of positive cases.

HHF35, antibody to common muscle actin; MFH, malignant fibrous histiocytoma; SMA, smooth muscle actin 

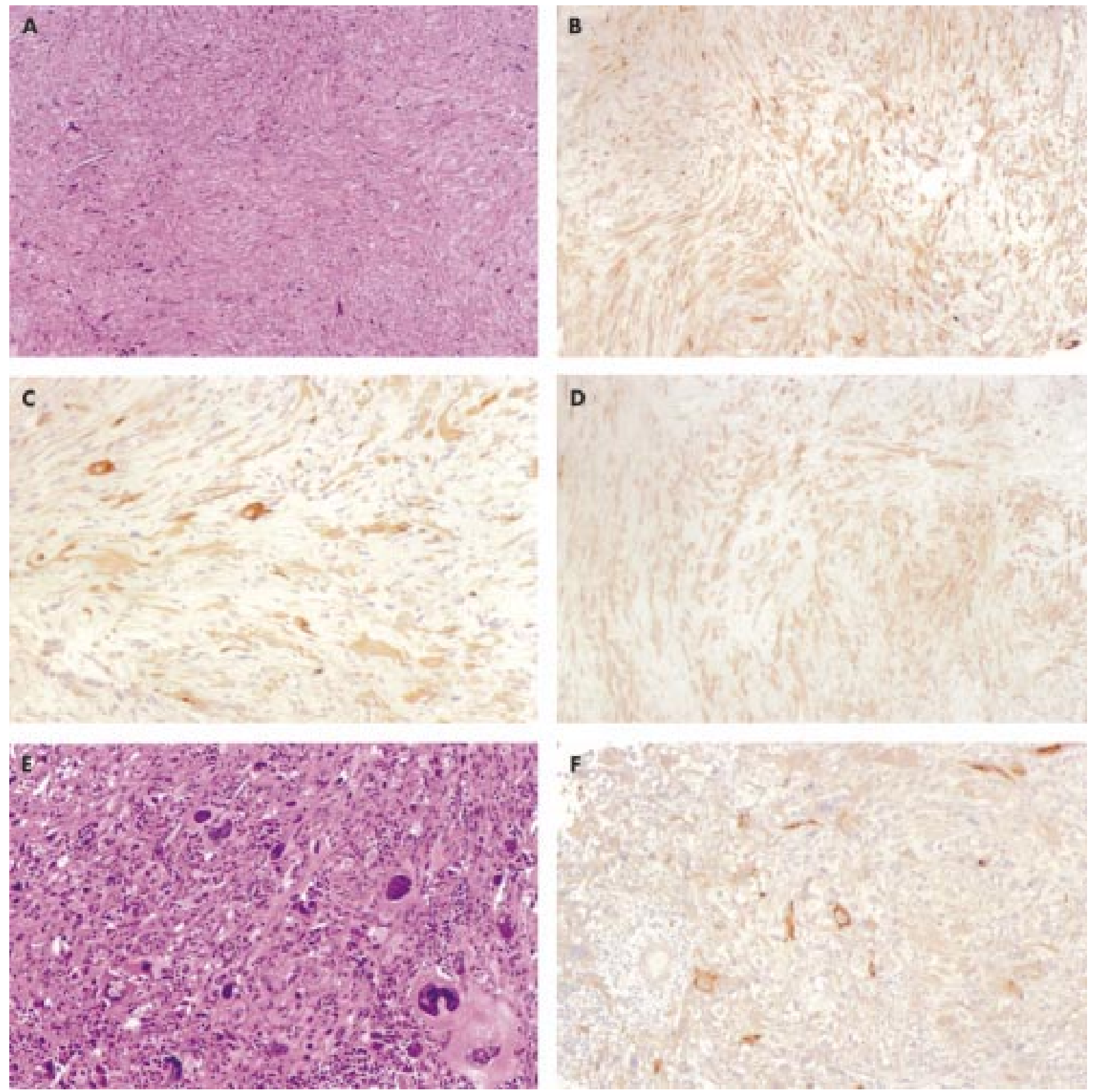

Figure 1 (A) Storiform-pleomorphic microscopic appearance in malignant fibrous histiocytoma (MFH) of bone arising in the right distal femur of a 55 year old man (haematoxylin and eosin stain). Diffuse immunohistochemical positive reactivity with (B) calponin, (C) $\alpha-S M A$, and (D) SM22 $\alpha$ in the same patient as (A). (E) Pleomorphic pattern with pronounced inflammatory cell infiltration in MFH of bone arising in the left distal femur of a 15 year old boy (haematoxylin and eosin stain). (F) Scattered tumour cells show positive cytoplasmic reactivity with calponin in the same patient as (E).

reaction mixture, and then the total volume was adjusted to $50 \mu \mathrm{l}$ with water. The parameters used for the amplification were 30 cycles of denaturation $\left(94^{\circ} \mathrm{C}, 40\right.$ seconds), annealing $\left(60^{\circ} \mathrm{C}, 30\right.$ seconds $)$, and polymerisation $\left(72^{\circ} \mathrm{C}, 90\right.$ seconds $)$. Sequences of the selected forward and reverse $5^{\prime}$ to $3^{\prime}$ primers used, and predicted products sizes were as follows: basic (hl) calponin, GAGTGTGCAGACGGAACTTCAGCC (forward), GTCTGTGCCCAACTTGGGGTC (reverse), 671 bp; neutral (h2) calponin, CTGCAGAGCGGGGTGGACATTGGC (forward), GCCGGCCTCCTCCTGGTAGTAAGG (reverse), 519 bp; $\alpha$-SMA, CCAGCTATGTGAAGAAGAAGAGG (forward), GTGATCTCCTTCTGCATTCGGT (reverse), 965 bp; SM22 $\alpha$, CGCGAAGTGCAGTCCAAAATCG (forward), GGGCTGGTTCTTCTTCAATGGGG (reverse), 928 bp; glyceraldehyde-3-phosphate dehydrogenase (GAPDH), CCCATCACCATCTTCCAGGA (forward), TTGTCATACCAGGAAATGAGC (reverse), $731 \mathrm{bp}$. The correctness of these primers has been confirmed previously. ${ }^{18}$ Linearity of the PCR products for calponins and SM22 $\alpha$ was obtained between 25 and 35 cycles, and for $\alpha$-SMA and GAPDH between 20 and 30 cycles. As a negative control, PCR reactions were conducted with each set of primers, but RNA was omitted in the RT reactions. After $1 \%$ agarose gel electrophoresis in the presence of $0.5 \mu \mathrm{g} / \mathrm{ml}$ of ethidium bromide, the PCR products were revealed by ultraviolet irradiation and the image captured and measured by Eagle Eye II still video system (Stratagene, La Jolla, California, USA). Variations in signal intensities between different agarose gels were corrected by using those of the molecular weight markers in each gel analysed. To assess the relative levels of expression, the signal intensity was subjectively graded by two independent observers (HY, KT) in a blind manner, from $(-),(+),(++)$, to $(+++)$, indicating negative expression and low, intermediate, 

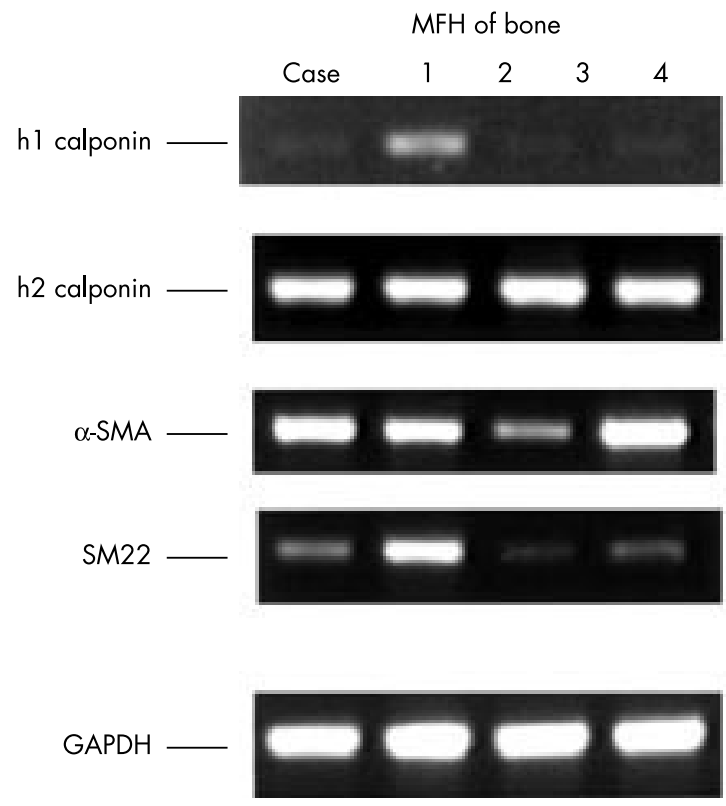

and high levels of expression, respectively. Negative results were confirmed at least twice.

\section{RESULTS}

\section{Immunohistochemical analysis}

Table 2 summarises the results of the immunohistochemical staining. Positive reactivity for $\alpha$-SMA, calponin, and SM $22 \alpha$ was found in nine, nine, and 18 of 19 cases of MFH of bone, respectively, although only one, two, and three cases of MFH of bone showed positive staining for desmin, MyoDl, and HHF35 (common muscle actin), respectively. Similarly, the 11 osteosarcoma cases were relatively frequently positive for $\alpha$-SMA (five cases), calponin (four cases), and SM $22 \alpha$ (seven cases), but showed less frequent positive staining for desmin (one case), MyoDl (none), and HHF35 (none). In contrast, the 11 cases of MFH of soft tissue cases were rarely positive for all of these muscle markers. Figure 1 shows the histological findings of two representative cases of MFH of bone with their immunohistochemical staining for calponin, $\alpha$-SMA, and SM22 $\alpha$. There was no correlation between the expression pattern of these muscle markers and the histological subtype in $\mathrm{MFH}$ of bone.

\section{Expression of mRNA for muscle markers in MFH of bone}

Figure 2 shows the results of the RT-PCR analysis for the expression of the basic (h1) and neutral (h2) calponin isoforms, $\alpha$-SMA, and SM22 $\alpha$ genes in four cases of MFH of bone and two representative cases of osteosarcoma. An mRNA transcript of the basic ( $\mathrm{hl}$ ) calponin gene was expressed in all of the four cases of MFH of bone at various levels, namely: $(++)$ in one case and $(+)$ in three cases. The smooth muscle differentiation specific genes, including $\alpha$-SMA and SM22 $\alpha$, were also expressed in all these cases to various degrees. In contrast, a case of osteoblastic osteosarcoma (case 2 in fig 2) showed complete lack of expression of basic (hl) calponin and SM22 $\alpha$ mRNA transcripts, with only an intermediate level of expression of $\alpha$-SMA mRNA. In contrast, the mRNA transcript for the neutral (h2) calponin, which is known to be expressed in both smooth muscle and non-smooth muscle tissues, ${ }^{15}{ }^{19}$ was uniformly expressed in all tumour samples examined.

\section{DISCUSSION}

We demonstrated, using both immunohistochemistry and RT-PCR analysis, that MFH of bone shows relatively frequent

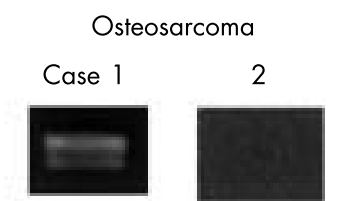

Figure 2 Reverse transcription polymerase chain reaction analysis for the expression of basic $(\mathrm{h} 1)$ and neutral (h2) calponin isoforms, $\alpha$ smooth muscle actin $(\alpha-S M A)$, and SM22 $\alpha$ genes in four cases of malignant fibrous histiocytoma (MFH) of bone and two representative cases

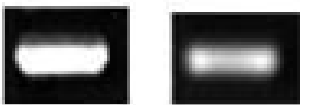
of osteosarcoma. GAPDH; glyceraldehyde-3-phosphate dehydrogenase.
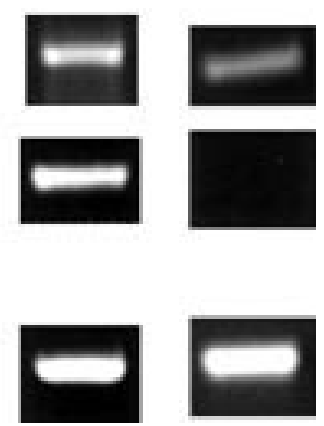

expression of smooth muscle markers, including $\alpha$-SMA, calponin, and SM $22 \alpha$. Of these markers, both calponin, specifically as basic (hl) calponin, and SM22 $\alpha$ are newly recognised, and are the earliest specific markers of differentiated smooth muscle cells. ${ }^{20-22}$ We have previously reported the relatively frequent expression of basic (hl) calponin (10 of 17 cases), SM22 $\alpha$ ( 14 of 17 cases), and $\alpha$-SMA ( 13 of 17 cases) mRNA transcripts in human osteosarcoma by RT-PCR analysis, and the expression of the basic (hl) calponin gene was significantly correlated with a favourable prognosis in this disease. ${ }^{18}$ We have also analysed the expression of basic (hl) calponin by immunohistochemical means in a series of soft tissue sarcomas, and only one of 11 cases of MFH showed positive reactivity for basic (hl) calponin..$^{23}$ These findings show that MFH of bone has a similar pattern of expression of smooth muscle differentiation specific markers to that seen in osteosarcoma, rather than to that seen in soft tissue MFH. In fact, we treat patients with MFH of bone in a similar manner to those with primary osteosarcoma. The comparable immunohistochemical findings presented in our study support this interpretation. With regard to the role of the antitumour activity of basic (hl) calponin, Horiuchi et al recently reported its possible role as a tumour suppressor in experimental human uterine leiomyosarcoma. ${ }^{24}$ However, in our present series no significant correlation between the expression of basic (hl) calponin and the prognosis of MFH of bone could be found (data not shown). "Malignant fibrous histiocytoma of bone has a similar
pattern of expression of smooth muscle differentiation
specific markers to that seen in osteosarcoma"

Although MFH of bone is a distinct clinicopathological entity, its true histogenesis is still debatable. Galmiche et al recently reported that human bone marrow stromal cells express various kinds of smooth muscle specific markers, including $\alpha$-SMA and calponin, suggesting that they originate from mesenchymal cells that differentiate along a vascular smooth muscle differentiation pathway. ${ }^{25}$ Interestingly, these "smooth muscle specific" markers are broadly expressed in a variety of tissues, such as normal and malignant breast tissue, ${ }^{26}$ salivary gland pleomorphic adenoma, ${ }^{27}$ and myofibroblastic sarcoma, ${ }^{28}$ and are postulated as novel myofibroblastic/myoepithelial differentiation molecular markers. From these observations, it is strongly suggested that 


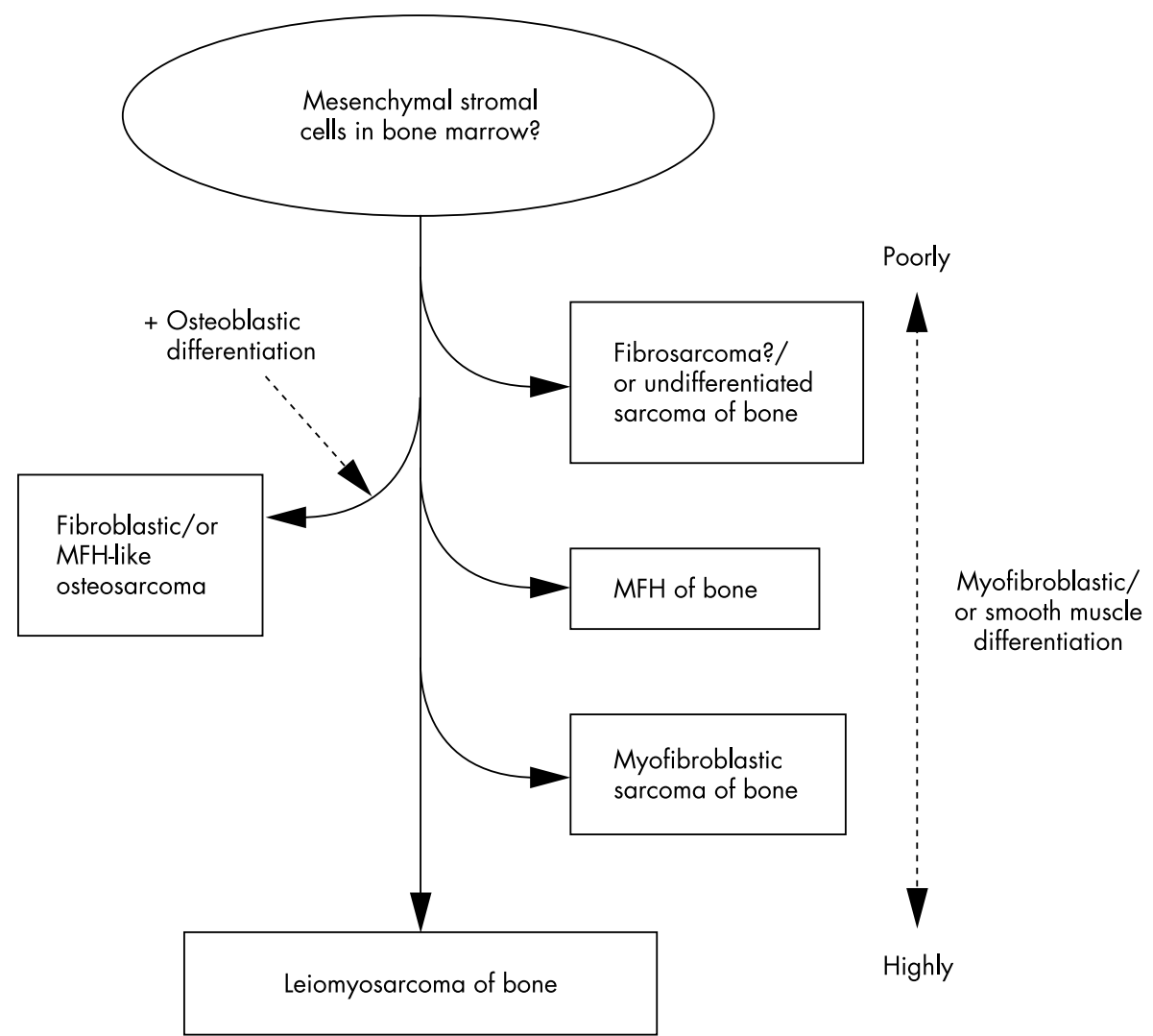

Figure 3 Hypothetical model of classification for spindle cell/or pleomorphic sarcomas arising in bone according to a spectrum of different degrees of myofibroblastic or smooth muscle cell differentiation. $\mathrm{MFH}$, malignant fibrous histiocytoma.

MFH of bone derives from mesenchymal stromal cells in bone marrow and has a more myofibroblastic differentiation than soft tissue MFH.

Primary leiomyosarcoma of bone is an extremely rare malignant bone tumour that was first described by Evans and Sanerkin in $1965,{ }^{29}$ and recently reviewed by Antonescu et al. ${ }^{30}$ It is defined as a malignant mesenchymal tumour primarily arising in bone, which is composed predominantly of spindle cells that definitely exhibit smooth muscle differentiation. Although its existence is still controversial, ${ }^{11}$ it is gradually being accepted as a true primary bone tumour as a result of refinements in immunohistochemical techniques and advances in the more precise interpretation of electron microscopic examinations. Immunohistochemically, the tumour cells generally show strong and diffuse positive reactivity for $\alpha$-SMA (100\%) and common muscle actin (HHF35) $(85 \%)$, and less frequently positive reactivity for desmin $(50 \%)$ (data on the positivity for calponin and SM $22 \alpha$ are not available).$^{30}$ However, immunohistochemical staining for these smooth muscle markers can be confusing because considerable numbers of cases of MFH of bone also show positive reactivity for these markers, as shown in our present study. Moreover, in a high grade, poorly differentiated leiomyosarcoma arising in bone, the differential diagnosis from $\mathrm{MFH}$, fibrosarcoma, and myofibroblastic sarcoma of bone may be quite difficult or impossible even by electron microscopic examination. Thus, it might be more practical to hypothesise that these primary malignant tumours arising in bone are a consecutive entity in a spectrum of different degrees of smooth muscle or myofibroblastic differentiation, rather than to prescribe them as independent clinicopathological entities (fig 3), although there is no convincing evidence that the expression pattern of smooth muscle markers is highly conserved during the pathogenesis of these sarcomas. Antonescu et al have also suggested that vascular smooth muscle cells or multipotential mesenchymal stem cells (that is, bone marrow stromal cells) capable of smooth muscle dif-

\section{Take home messages}

- Smooth muscle/myofibroblastic markers, including $\alpha$ smooth muscle actin, calponin, and SM22 $\alpha$, are expressed relatively frequently in malignant fibrous histiocytoma (MFH) of bone compared with soft tissue MFH

- This pattern of expression is similar to that seen in osteosarcoma

- MFH of bone may have a bone marrow stromal cell origin, with a common histogenetic pathway to that of primary leiomyosarcoma of bone

ferentiation could be possible origins for intraosseous leiomyosarcoma, ${ }^{30}$ supporting our hypothesis. Moreover, a recent cytogenetic study using a comparative genomic hybridisation technique in leiomyosarcomas at various sites including bone, compared with MFH, demonstrated that both types of tumours had a similar pattern of recurrent genomic imbalances, suggesting that MFH is a morphological modulation in the tumour progression of other sarcomas, particularly leiomyosarcoma. ${ }^{31}$

In conclusion, we have demonstrated the relatively frequent expression of smooth muscle/myofibroblastic markers, including $\alpha$-SMA, calponin, and SM22 $\alpha$, in MFH of bone, which is similar to the pattern seen in osteosarcoma rather than that seen in soft tissue MFH. Our present study also suggests a possible bone marrow stromal cell origin for MFH of bone, with a common histogenetic pathway to that of primary leiomyosarcoma of bone.

\section{ACKNOWLEDGEMENTS}

We thank Ms H Funai (Department of Pathology, Osaka Medical Center for Cancer and Cardiovascular Diseases) for technical help in the immunohistochemical study. 


\section{Authors' affiliations}

T Ueda, A Myoui, S Joyama, H Yoshikawa, Department of Orthopaedic Surgery, Osaka University Graduate School of Medicine, 2-2 Yamada-oka, Suita, Osaka 565-0871, Japan

N Araki, Department of Orthopaedic Surgery, Osaka Medical Center for Cancer and Cardiovascular Diseases, Osaka 540-0006, Japan

M Mano, S Ishiguro, Department of Pathology, Osaka Medical Center for Cancer and Cardiovascular Diseases

H Yamamura, K Takahashi, Department of Medicine, Osaka Medical Center for Cancer and Cardiovascular Diseases

I Kudawara, Department of Orthopaedic Surgery, Osaka National Hospital, Osaka 540-0006, Japan

\section{REFERENCES}

1 Dorfman HD, Czerniak B. Bone tumors, 1st ed. St Louis: Mosby, 1998

2 Feldman F, Norman D. Intra- and extraosseous malignant histiocytoma (malignant fibrous xanthoma). Radiology 1972;104:497-508

3 Mirra JM, Bullough PG, Marcove RC, et al. Malignant fibrous histiocytoma and osteosarcoma in association with bone infarcts: report of four cases, two in caisson workers. J Bone Joint Surg

1974:56A:932-40.

4 Dahlin DC, Unni KK, Matsuno T. Malignant (fibrous) histiocytoma of bone-fact or fancy? Cancer 1977;39:1508-16.

5 Huvos AG. Malignant fibrous histiocytoma. In: Mitchell J, ed. Bone tumors: diagnosis, treatment, and prognosis, 2nd ed. Philadelphia: WB Saunders, 1991:497-521.

6 Capanna R, Bertoni F, Bacchini P, et al. Malignant fibrous histiocytoma of bone. The experience at the Rizzoli Institute: report of 90 cases. Cancer 1984;54:177-87

7 Huvos AG, Heilweil M, Bretsky SS. The pathology of malignant fibrous histiocytoma of bone. A study of 130 patients. Am J Surg Pathol 1985:9:853-71.

8 Naka T, Fukuda T, Shinohara $N$, et al. Osteosarcoma versus malignant fibrous histiocytoma of bone in patients older than 40 years. Cance 1995;76:972-84.

9 Nakashima Y, Morishita S, Kotoura Y. Malignant fibrous histiocytoma of bone: a review of 13 cases and an ultrastructural study. Cancer 1985;55:2804-1 1.

10 Nishida J, Sim FH, Wenger DE, et al. Malignant fibrous histiocytoma of bone: a clinicopathologic study of 81 patients. Cancer 1997;79:482-93.

11 Unni KK. Dahlin's bone tumors, 5th ed. Philadelphia: Lippincott-Raven, 1995

12 Brooks JSJ. Immunohistochemistry in the differential diagnosis of soft tissue tumors. In: Weiss SW, Brooks JSJ, eds. Soft tissue tumors. Baltimore: Williams \& Wilkins, 1996:65-128.

13 Perez-Bacete MJ, Llombart-Bosch A. FU-3 monoclonal antibody: a specific marker for malignant fibrous histiocytoma? An analysis of 32 malignant soft tissue and bone sarcomas. Virchows Arch 1994:424:243-7.

14 Yoshikawa H, Rettig WJ, Lane JM, et al. Immunohistochemical detection of bone morphogenetic proteins in bone and soft-tissue sarcomas. Cancer 1994;74:842-7
15 Masuda H, Tanaka K, Takagi M, et al. Molecular cloning and characterization of human non-smooth muscle calponin. J Biochem 1996; 120:415-24.

16 Yamamura $\mathbf{H}$, Masuda $\mathrm{H}$, Ikeda W, et al. Structure and expression of the human SM22 $\alpha$ gene, assignment of the gene to chromosome 11, and repression of the promoter activity by cytosine DNA methylation. J Biochem 1997; 122:157-67.

17 Shi SR, Key ME, Kalra KL. Antigen retrieval in formalin-fixed, paraffin embedded tissues: an enhancement method for immunohistochemical staining based on microwave oven heating of tissue sections. J Histochem Cytochem 1991;39:741-8.

18 Yamamura $\mathbf{H}$, Yoshikawa $H$, Tatsuta $M$, et al. Expression of the smooth muscle calponin gene in human osteosarcoma and its possible association with prognosis. Int J Cancer 1998;79:245-50.

19 Applegate D, Feng W, Green RS, et al. Cloning and expression of a novel acidic calponin isoform from vascular smooth muscle. J Biol Chem 1994;269: 10683-90.

20 Duband JL, Gimona M, Scatena M, et al. Calponin and SM22 as differentiation markers of smooth muscle: spatiotemporal distribution during avian embryonic development. Differentiation 1993;55:1-11.

21 Li L, Miano JM, Cserjesi P, et al. SM22 $\alpha$, a marker of adult smooth muscle, is expressed in multiple myogenic lineages during embryogenesis. Circ Res 1996;78:188-95

22 Takahashi K, Nadal-Ginard B. Molecular cloning and sequence analysis of smooth muscle calponin. J Biol Chem 1991;266:13284-8.

23 Ono H, Yoshikawa H, Ueda T, et al. Expression of smooth muscle calponin in synovial sarcoma. Sarcoma 1999:3:107-13.

24 Horiuchi A, Nikaido T, Taniguchi S, et al. Possible role of calponin hl as a tumor suppressor in human uterine leiomyosarcoma. J Natl Cancer Inst 1999;91:790-6.

25 Galmiche MC, Koteliansky VE, Briere J, et al. Stromal cells from human long-term marrow cultures are mesenchymal cells that differentiate following a vascular smooth muscle differentiation pathway. Blood 1993;82:66-76.

26 Lazard D, Sastre X, Frid MG, et al. Expression of smooth muscle-specific proteins in myoepithelium and stromal myofibroblasts of normal and malignant human breast tissue. Proc Natl Acad Sci U S A 1993;90:999-1003.

27 Savera AT, Gown AM, Zabro RJ. Immunolocalization of three nove smooth muscle-specific proteins in salivary gland pleomorphic adenoma: assessment of the morphogenetic role of myoepithelium. Mod Pathol 1997; 10:1093-100.

28 Mentzel T, Dry S, Katenkamp D, et al. Low-grade myofibroblastic sarcoma: analysis of 18 cases in the spectrum of myofibroblastic tumors. Am J Surg Pathol 1998;22:1228-38.

29 Evans DMD, Sanerkin NG. Primary leiomyosarcoma of bone. J Pathol 1965;90:348-50

30 Antonescu CR, Erlandson RA, Huvos AG. Primary leiomyosarcoma of bone: a clinicopathologic, immunohistochemical, and ultrastructural study of 33 patients and a literature review. Am J Surg Pathol 1997;21:1281-94.

31 Derré J, Lagacé R, Nicolas A, et al. Leiomyosarcomas and most malignant fibrous histiocytomas share very similar comparative genomic hybridization imbalances: an analysis of a series of 27 leiomyosarcomas. Lab Invest 2001;81:21 1-15. 